\title{
Madres e hijos/as de locutorio Lucía Alvites
}

\author{
Editorial Perú Migrante, Lima, Perú, 2001, 70 págs. \\ Ricardo Jiménez A. \\ Proyecto Perú Migrante, Lima. Email: ricardojimenez006@gmail.com
}

Desde Patterson, Estados Unidos, Génova, Italia, Buenos Aires, Argentina o Santiago de Chile, desafiando hasta cientos de miles de kilómetros de distancia, más de medio millón de mujeres tejen porfiadamente, cotidianamente, lazos de amor y cuidado con sus hijos e hijas en Perú. El hilo con que hilvanan estas nuevas formas de ser y hacer familias, transformando el mundo y transformándose, es el cable telefónico. Un nuevo cordón umbilical por el que van y vienen los afectos y cuidados, los enojos y discusiones, alimentando las nuevas familias bi o transnacionales.

Las voces de estas protagonistas del futuro, sus específicas vulnerabilidades y crecimientos como migrantes que redefinen su biografía, su familia y sus sociedades, son recogidas y presentadas de manera sistemática y ricamente contextualizadas en el libro "Madres e hijos/as de locutorio. La búsqueda de una familia sin fronteras", de la socióloga peruana Lucía Alvites. Se trata de la primera investigación publicada por esta investigadora de 26 años de edad, egresada de la Universidad Nacional Mayor de San Marcos de Lima y tesista del Magíster en Género y Estudios Latinoamericanos de la Universidad de Chile.

El libro, que ya es posible de encontrar en versión virtual en internet, ofrece una perfecta combinación de rigurosidad científica y sensibilidad a escala humana. Se nota en él la convergencia de una serie de factores, no necesariamente explícitos en el mismo texto, pero que resultan fundamentales para explicar su acertado enfoque y la oportunidad de su presentación en el tiempo presente. Una especie de "tormenta perfecta" catalizada en este trabajo.

En primer lugar, la experticia individual y colectiva. Los estudios sistemáticos y especializados de la autora en la temática específica de migraciones datan desde hace cinco años, las entrevistas que sirven de fuentes a la investigación, tanto a madres residentes en diversos lugares del mundo como a hijos e hijas en diversas regiones de Perú, fueron recogidas desde hace tres. En este período, la investigadora recogió también los saberes colectivos de asociaciones de migrantes y sus familiares, de funcionarios públicos que tratan con migración, y especialmente comunidades peruanas en el exterior, a través de redes internacionales en las que participa y cooperaciones con entidades internacionales y públicas de Perú y otros países dedicadas a su abordaje, incluyendo numerosos encuentros, seminarios y reuniones internacionales especializadas. Adiciona a este bagaje un elemento que no es menor y que permite explicar buena parte de la sensibilidad mostrada en el texto. Ha vivido personalmente la experiencia biográfica migratoria durante más de dos años en Chile.

Pero no sólo rigor científico y sensibilidad caracterizan el contenido del libro, sino también una clara vocación política, en el sentido de estar animado por un permanente énfasis ciudadano, que interpela a las políticas públicas migratorias y se posiciona en un enfoque de derechos, género e interculturalidad. Las labores profesionales de la autora, centradas justamente en la promoción de un programa de políticas públicas para los ciudadanos y ciudadanas migrantes por parte del Estado peruano y de los bloques regionales andinos, suramericanos y latinoamericanos, se ve reflejada.

En segundo lugar, se perciben las sinergias que están a la base tanto del estudio como de la investigación. En este ámbito, destaca el prólogo, escrito con sólido conocimiento de la temática, por Aída García Naranjo, reciente ex Ministra de la Mujer de Perú, figura del progresismo peruano y especialista con dilatada trayectoria en cuestiones de género y migratorias, que al tiempo que refuerza el implícito político programático del libro, viene a realzar una convergencia de altas experticias y sensibilidades felizmente conjugadas, en las que se incluye de manera decisiva el Proyecto Perú Migrante, que ha hecho posible la investigación y publicación. Una iniciativa de envergadura para promover una migración con derechos en el 
Perú y algunos países de mayor magnitud de peruanos emigrados en Europa y Suramérica, que aúna esfuerzos de la Unión Europea, la Defensoría del Pueblo de Perú, ProgettoMondo Mlal y Fondazione ISMU de Italia, y Forum Solidaridad Perú, prestigiosa entidad civil con veinte años de labor social en Perú, que es parte de la Red para la Migración y el Desarrollo - PEMIDE de Perú, cuyas numerosas entidades civiles están en diálogo permanente con este proyecto. Finalmente, la propia actividad profesional de la autora, Asesora en temas migratorios del Parlamentario Andino peruano y del destacado intelectual y político, Alberto Adrianzén, así como su cooperación permanente con la Dirección especializada en migraciones del Ministerio de Relaciones Exteriores peruano, a cargo del embajador Marco Núñez Melgar, sociólogo y experto en la temática, terminan de configurar estas amplias convergencias de esfuerzos comunes que se han visto reflejadas en la mirada integral de la investigación y que pudo apreciarse del todo en la presentación pública del libro que contó con comentaristas representantes de estas diversas instituciones.

Finalmente, parte importante de la multiplicidad de elementos positivos que explican lo acertado de esta publicación, lo constituye su oportunidad, su sentido de utilidad para el momento contingente en que sale a la luz, para responder a la urgente necesidad de enriquecer los debates y abordajes de una galopante crisis migratoria, que se combina con crisis múltiples y exigencias de adecuación de los sistemas políticos y ciudadanos a inicios del siglo XXI.

Como el mismo texto señala, mientras la migración adquiere características inéditas en la historia: masividad, extensión, diversificación, feminización y politización, en interacción con las persistentes desigualdades, los avances en transportes y comunicación, y la creciente interconexión global, el sistema de Naciones Unidas informa en el año 2010 que la mayoría de los Estados del mundo muestra una crónica falta de respuestas adecuadas en política públicas para su tratamiento, generando agudas violaciones a los derechos humanos de los migrantes e impactos negativos en diversos ámbitos que afectan al conjunto de las sociedades.

Urgen entonces estudios serios que sirvan de insumos a las nuevas respuestas y regulaciones, de manera viable y deseable, para hacer de la migración una opción libre y digna, articulada con democracias justas e incluyentes, y no un colapso evitable de los derechos humanos. Y el texto de Lucía Alvites es un ejemplo de ello. Pero además busca también al lector no especializado por su claridad y sencillez de lenguaje, así como por la belleza del formato, fruto del trabajo de los jóvenes y talentosos Claudia Denegri, diseñadora, y Renato Pita Silber, diagramador. Hay en el libro una implícita pero bien definida vocación de divulgación, de enriquecimiento de la opinión y la ciudadanía a la más amplia escala posible, sin perder rigurosidad científica.

La estructura del estudio se soporta en una metodología cuali-cuantitativa que complementa de manera impecable, coherente, valiosas fuentes bibliográficas y documentales, con ricas entrevistas semi estructuradas a madres e hijos resientes en países distintos a los de su familiar directo y vinculados cotidianamente por el teléfono, que en la mayoría de los casos es para las madres un teléfono de "locutorio", pequeñas cabinas individuales en locales comerciales especializados en ofrecer ese servicio. A partir de ellas, la autora construye una visión de conjunto, esencial y detallada, del fenómeno de estas maternidades y filiaciones en juego y reconfiguración por la distancia física y la cercanía afectiva y de responsabilidades, que humaniza, como ella misma explícitamente se lo propone y nos lo propone, a la cifra, pero que no pierde por eso la sólida fundamentación objetiva, de la cual es muestra la acotada y rica, casi exhaustiva, bibliografía que nutrió la investigación.

El estilo de exposición está claramente en tensión entre esos dos objetivos de rigurosidad y sensibilidad, es manifiesta la intencionalidad de eximir al texto de recursos de erudición y especialización que no sean estrictamente necesarios para una imprescindible descripción y contextualización. Al mismo tiempo, nos entrega figuras y metáforas que sin aspavientos embellecen nuestra mirada y comprensión, que encuentran luz explicativa cuando nos enteramos que la autora es además poeta de su generación.

En suma, el libro parece querer realizarse en el aporte a los lectores especializados e interesados, al mismo tiempo que en la divulgación amplia a los ciudadanos comunes, a quienes pretende hacer ameno y conmovedor el fenómeno social de las migraciones, quizás para que se miren en la migración como en un espejo y se pregunten por la imagen que reciben de vuelta. 
Se juega en esa vocación su limitación más notoria: el carácter introductorio e incompleto. Como si se tratará de una novela por entregas, nos parece casi un primer capítulo, un exordio que reclama desarrollarse, y así lo señala el mismo trabajo al describir su contenido como una "pálida muestra" de la riqueza informativa que proporcionó la investigación, y referir las posibilidades abiertas como "un gran campo social por explorar de manera útil". Y tal vez radica allí su objetivo más fundamental, tocar las puertas del interés público para abrir cauces a lo posible y deseable, para dignificar aún más la vida de esas mujeres y esos niños y niñas, al tiempo que el de todos y todas.

Queremos que esa limitación sea entonces al mismo tiempo una promesa, para que la joven y talentosa autora continué, ojalá prontamente, haciéndonos llegar nuevos desarrollos investigativos que nos permitan escuchar las voces, normalmente en silencio público, de las nuevas familias que ayudan a repensar las fronteras; las geográficas, las del pensamiento y las del alma. 